\title{
MANUEL REVUELTA GONZÁLEZ (1936-2019), HISTORIADOR DE LA VIDA RELIGIOSA EN LA ESPAÑA CONTEMPORÁNEA
}

\author{
ALFREDO VERDOY HERRANZ ${ }^{1}$
}

RESUMEN: El magisterio del P. Revuelta, además de amplio y versátil, resulta clave para comprender dentro de su propio contexto, el contexto revolucionario y liberal de los siglos XIX y XX, la vida de los religiosos españoles a lo largo de estos dos siglos. Revuelta dedicó tiempo a exhumar documentos y reconstruir históricamente la vida de miles de religiosos que, por fidelidad a su vocación personal y a la orden religiosa en la que se consagraron a Dios, acabaron sufriendo en sus propias carnes los efectos más negativos de la Revolución liberal española. Los liberales españoles aprobaron decretos, en el fondo antiliberales e inconstitucionales, los famosos decretos desamortizadores, que pusieron fuera de la ley a miles de religiosos: los famosos exclaustrados. Miles de españoles, antiguos monjes, monjas, frailes y religiosos, se vieron, de la noche a la mañana, empobrecidos y sin apenas futuro dentro del territorio nacional. En la segunda parte de esta colaboración, presentamos los intentos de reconstrucción de la vida religiosa en la España de la Restauración borbónica.

PALABRAS CLAVE: Revolución liberal; desamortización; exclaustración; exclaustrados; frailes; monjas y vida religiosa; Restauración.

\section{Manuel Revuelta González (1936-2019), Historian of religious life in contemporary Spain}

ABSTRACT: The versatile and expansive magisterium of Fr. Revuelta is crucially important to understand, within its own context (the revolutionary and liberal context of the 19th and 20th centuries), the lives of the Spanish religious men and women throughout these two centuries. Revuelta invested an immense amount of time to recover documents and with these texts to reconstruct the lives of thousands of religious men and women who suffered the most adverse effects of the Spanish liberal Revolution because of their faithfulness to their vocation and to their religious congregations. With the approval of the «confiscator decrees», Spanish liberal politicians outlawed religious, essentially illegalizing their lives as religious. As a result, monks, nuns, and friars found themselves suddenly poor and without a future inside their national territories. In the second part of this article, we will point to the attempts to reconstruct religious life during the Borbonic Restoration period.

KEY WORDS: Liberal Revolution; confiscation; exclaustration; friars; nuns; religious life; Restoration.

1 Profesor de la Facultad de Teología, Universidad Pontificia Comillas. Correo electrónico: averdoy@comillas.edu. 


\section{INTRODUCCIÓN}

Si tuviésemos que identificar al Padre Manuel Revuelta González (19362019) con algunos de los cientos de historiadores, ensayistas, periodistas y redactores de crónicas y memorias con los que a lo largo de su carrera se tropezó y estudió, éstos serían: el clérigo catalán Jaime Balmes (18101848)²; el periodista católico y emprendedor cultural, el mallorquín José María Quadrado (1819-1896) y el barcelonés Josep Coroleu (1839-1895), quien lamentaba que la Iglesia dejase de ser la casa común de todos para dividirse y partirse en iglesias donde van los ricos e iglesias donde siguen los pobres. Próximos a ellos, aunque por razones muy diferentes, colocaríamos al Padre Luis Martín (1846-1906), General de la Compañía de Jesús, paradigma y prototipo del buen gobernante (Revuelta, 2002, p. 64), y al periodista católico Félix Sardá y Salvany (1841-1916) (Moliner, 2000), más en cuanto escritor, analista social y hombre de acción entre otras referencias que en cuanto polemista y acérrimo defensor de un catolicismo que más que unir separaba y desunía (Revuelta, 2002, pp. 79-80).

Si tuviésemos que identificarlo, en segundo lugar, con alguno de los muchos y abundantes grupos sociales a los que su innata curiosidad y su afán por seguir de cerca llevó, este grupo sería el de los exclaustrados. Un numeroso grupo de personas que, en muy poco tiempo, sufrieron las consecuencias de leyes que no entendían, de leyes que alteraron para siempre el orden de sus vidas y el sentido religioso, humano y hasta político de su vocación religiosa. Ese grupo no es otro que el de los exclaustrados: religiosos, frailes y monjas, representantes de la vida religiosa durante los años finales del Antiguo Régimen.

\section{MANUEL REVUELTA GONZÁLEZ. EL PORQUÉ DE UN INTERÉS: LOS EXCLAUSTRADOS}

Inspirado, tal vez guiado por la imagen que el periodista y autor teatral Antonio Gil de Zárate (1793-1861) nos dejara de los exclaustrados (Revuelta, 1989, p. 293), Revuelta se constituyó no solo en el iniciador de los estudios sobre los exclaustrados, sino en su máximo y más consumado especialista.

2 Balmes es citado, por ejemplo, en dieciocho ocasiones en su libro La Iglesia española en el siglo XIX. Desafíos y propuestas (cf. Revuelta, 2005, p. 277).

3 Quadrado lo es en diez ocasiones (cf. Revuelta, 2005, p. 283). 
Todo aquel que quiera analizar y profundizar en el estudio de los exclaustrados, podrá hacerlo gracias a las investigaciones y a las conclusiones a las que este estudioso llegó a lo largo de su carrera investigadora.

¿Qué razones llevaron al Padre Revuelta a preocuparse y ocuparse de los religiosos y en concreto de los exclaustrados? A nuestro juicio fueron tres las razones que alimentaron su querencia y cercanía al mundo de los exclaustrados: su propia vocación religiosa; sus ajustadas apreciaciones como diseccionador del factor religioso, en concreto de la religión católica, en la España contemporánea y, finalmente, su propio celo apostólico escondido en las cenizas y brasas del gran incendio de la exclaustración y que con el paso del tiempo volverían a llamear cuando la vida religiosa se restaurara y fortaleciera en la España contemporánea, de la cual él siempre se sintió un agradecido representante y miembro.

Expliquémoslos. Uno de los textos más queridos del religioso y sacerdote jesuita que fue Revuelta es un texto poco conocido, Vivencias cristianas, y del que él mismo afirma en sus Memorias: "No quiero omitir, por la sinceridad que manifesté al escribirlo, mis vivencias autobiográficas en el libro Felicidades, Jesucristo, coordinado por Joaquín Luis Ortega en la BAC. Bajo el título de Vivencias cristianas, es una confesión de fe en lo que Jesucristo ha significado en mi vida. Lo expresaba en cuatro suspiros: semilla, llamada, seguimiento y fidelidad. Otros autores expresaron su visión teórica de Jesucristo. Yo expresé mis sentimientos personales, que impresionaron a muchos» (Revuelta, 2000, pp. 249-251 y 2019, p. 97). La semilla de su vocación, las semillas de su vida cristiana y humana son las de un niño nacido el primer día del año en el que estallaba la Guerra civil española y criado en el seno de una familia católica tradicional y muy castellana. «Mis primeras experiencias de Jesús fueron las de un niño de una familia cristiana en un pueblecito de Tierra de Campos. Eran mensajes que penetraban a través de oraciones, imágenes y costumbres [...] como la de las mujeres palentinas que, en Nochebuena, dejaban prendida la lumbre de la trébede porque pasaba la Virgen María a calentar los pañales del Niño Jesús. Las vivencias caseras se completaban con las devociones populares. ¡Qué impresiones tan hondas en la Semana Santa! [...] El respeto al Cristo dolorido se trocaba en alegría durante el mes del Corazón de Jesús, cuando los chiquitos lucíamos detentes, entre aromas de azucenas y silbidos de vencejos. La primera comunión coronaba devociones infantiles». Experiencias y vivencias tal vez comunes no solo en el tiempo, sino en la hondura religiosa y humana a las que a su modo y dentro de su contexto temporal experimentaron cuando niños y niñas sus más adelante queridos exclaustrados. 
Su llamada a la vida religiosa, como las que más de ciento cincuenta años antes fueron las de sus grandes amigos los exclaustrados, la sintió en un colegio regentado por religiosos: el colegio de los jesuitas de Valladolid, el Colegio de San José (Fernández, 1981), «donde estudié el bachillerato». Aquel colegio «era terreno abonado para que la semilla estallara en brotes de primavera». Fue en este colegio donde a la edad de los doce años, leyó, "por primera vez el evangelio entero, durante las misas en latín», se «entusiasmó y aprendí de memoria el sermón de la Montaña. Y sentí que Jesús me dirigía sus palabras: el que quiera venir en pos de mí... La vocación avanzaba paso a paso... Me costó mucho seguirla, porque tuve que dejar a mis padres, siendo hijo único». En este punto como en tantos otros, el religioso Revuelta se identificó con las raíces vocacionales de los que más adelante serían sus compañeros durante su vida religiosa. Compañeros misteriosos, pero no distantes, en los que supo leer con claves de perseverancia y esperanza los misterios de la llamada divina en medio de un mundo adverso.

Fruto de la llamada, como en tantos otros casos, fue el seguimiento a Jesucristo. Un seguimiento, en su caso, estrecho, diario e íntimo. Seguimiento que culminó con su ordenación sacerdotal y con un ejercicio del sacerdocio muy parecido al que miles y miles de exclaustrados y religiosos encarnaron en sus vidas: el del esfuerzo, la perseverancia y también el de la cultura, la ciencia, la docencia y la escritura.

Finalmente, la fidelidad. Una fidelidad como en el caso de sus admirados exclaustrados, «silenciosa» y «sin otra aspiración que el servicio a los demás, al igual que el Maestro, que vino no a ser servido, sino a servir» (Ortega, 1999, pp. 249-251).

A este caudal de vida habrá que sumar a la hora de entender las opciones historiográficas del religioso Revuelta, su capacidad analítica, diseccionadora más bien, que le llevó a sopesar de manera privilegiada la importancia de la religión católica en la España contemporánea. La religión católica, representaba, entre otras cosas, dentro de la agitada vida política española, «la expresión anímica de los españoles». La representaba de tal manera que la religión, se quiera o no reconocer, «constituía gran parte de la nervadura y del esquema mental de los españoles», por lo que nadie podía «ignorarla o prescindir de ella». Más aún, muchos españoles, entre ellos los religiosos y las religiosas, la tomaban y vivían "por encima de cualquier otro valor». Razón, concluimos nosotros, por la que no podía dejar al margen de su esfuerzo intelectual a un numeroso grupo dentro de las minorías españolas del momento como fueron los consagrados a Dios en religión y para los que la vivencia de lo religioso fue ganando personalmente en intensidad mientras en muchos casos se perdía en extensión $\mathrm{Si}$ «los hombres del XIX vibraron 
ante la idea religiosa con más intensidad tal vez que los de épocas pasadas», los que más sobresalieron siguiendo este modelo y estilo de vida fueron los religiosos (Revuelta, 1989, pp. 216, 217 y 221). Revuelta, como veremos a lo largo de estas páginas, no los estudiará fuera de contexto, como huesos sueltos de un cuerpo que no se acaba de inhumar, sino dentro del clima cultural y vital que les tocó vivir.

El jesuita y religioso Revuelta González revestido y lleno de agradecimiento y de conocimientos más que suficientes, tal vez se lanzó a recorrer sistemáticamente un camino preñado de esperanza, que muy pocos habían recorrido, poniéndose como meta mantener vivas las cenizas que escondían las brasas todavía calientes de la vida religiosa de los primeros años del siglo XIX y de esta manera recuperar su memoria, única manera de hacer justicia y reconciliar para siempre las dos Españas.

Presentada su figura y sus motivaciones historiográficas, nuestro homenaje al Padre Revuelta tendrá dos objetivos: mostrar, por una parte, sus esfuerzos y logros en favor de los exclaustrados y ofrecer, por otra, una leve panorámica de la restauración de la vida religiosa en la España contemporánea.

\title{
3. MANUEL REVUELTA GONZÁLEZ, ADALID Y ESTUDIOSO DE LA EXCLAUSTRACIÓN Y DE LOS EXCLAUSTRADOS
}

\author{
«La exclaustración es digna de una memoria \\ histórica por su profundo sentido religioso y \\ sus consecuencias sociológicas, económicas \\ y culturales». (Revuelta, 2010, p. 44)
}

Presentemos, pues, el significado de la exclaustración y la suerte de los exclaustrados. ¿Qué entiende por exclaustración? La exclaustración, en su caso, de las órdenes e institutos religiosos equivale a «la supresión de los monasterios o conventos hecha por los poderes civiles, con la consiguiente negación a las comunidades religiosas de su existencia legal, y la prohibición de hacer vida común [...] Generalmente la exclaustración va acompañada de la desamortización, que implica la incautación por el Estado de los bienes de las comunidades suprimidas, a la que suele seguir la venta en pública subasta. La exclaustración es en España un suceso típicamente decimonónico, ligado estrechamente a la política religiosa de los partidos liberales» (Revuelta, 2005, pp. 114-115). Fenómeno no solo español, sino típico de los regímenes liberales europeos, presente en todos los países donde la vida religiosa tenía una fuerte presencia antes de la Revolución Francesa. 
Consideramos que fue en la introducción a la ponencia que tuvo en el Congreso que se celebró en Roma el año 2010 bajo los auspicios de la orden de San Agustín, donde Revuelta recapituló todos sus esfuerzos investigadores y divulgadores para ofrecernos el marco general de la exclaustración: «La supresión de las órdenes religiosas en la edad contemporánea, afirmó en aquella ocasión, ha sido uno de los acontecimientos más dolorosos de la historia de la Iglesia. Sus consecuencias han sido inmensas, por el menoscabo que produjo en la vida católica y por sus repercusiones culturales, sociales y económicas en las naciones afectadas». Una supresión, para más demérito de los que la propiciaron y fomentaron, prolongada, con «continuidad cronológica». Continuidad que alcanzó, en la práctica, dos siglos: «desde mediados del siglo XVIII» hasta los años centrales del siglo XX bajo «los regímenes comunistas». Tiempo en el que la política y los esquemas ideológicos y sociopolíticos, nacidos durante la Ilustración y la Revolución y continuados y acrecentados durante el liberalismo y el socialismo, acabaron imponiendo sus "peculiares controles, reformas o persecuciones a la Iglesia, en las que casi siempre se ha golpeado a las comunidades religiosas. En cada caso se trataba de aplicar una determinada política religiosa, con mayor o menor ingrediente anticlerical». Y continúa: «si reuniéramos las noticias sobre las supresiones de comunidades religiosas acaecidas en momentos y lugares diferentes, obtendríamos la visión global de un fenómeno exclaustrador de alcance planetario a lo largo de dos siglos» (Revuelta, 2010, pp. 17-18).

Los tiempos fuertes de este proceso se concentran en los años finales del siglo XVIII y en las primeras décadas del XIX. En el caso español, entre 1790 y 1837; durante este largo período, «se ensayaron todos los modelos de exclaustración y se pusieron todos los argumentos para ejecutarla». No fue, por lo tanto, «un movimiento espontáneo, sino planificado: no exclusivo de ningún país, sino difundido por todos» (Revuelta, 2010, p. 18).

Lo que hoy sería inaceptable políticamente, dado que iría en contra de los derechos humanos más elementales, hace justamente algo más de dos siglos fue moneda común en la Europa liberal que luchaba por desprenderse de la tutela de la Iglesia y de paso por apoderarse de sus bienes materiales y patrimoniales, así como del prestigio y de la autoridad moral que la vida religiosa y el clero tenían por entonces.

Para acometer, pues, una política que a la postre acabó marginando a uno de los grupos sociales más privilegiados de aquel entonces, los gobiernos liberales, también los españoles, adujeron una serie de motivos, que pueden clasificarse en tres grupos: motivos político-reformadores de la Iglesia, demográficos y económicos. Por los primeros, los políticos, educados, imbuidos por un regalismo subido de tono, así como deseosos de ejercer un cierto 
control sobre la Iglesia para reformarla, primero, y tenerla a su disposición, después, se lanzaron a unas prácticas políticas de las que salieron malparadas y heridas de muerte las congregaciones religiosas y todos sus miembros. Los liberales, en suma, desde estos supuestos, pretendían una reforma de la Iglesia; una reforma, eso sí, controlada por el Estado, lo que implicaba despojar a la Iglesia de su «independencia económica». Operación en nada sencilla y que implicaba, como primera medida, la desamortización de sus bienes y el sostenimiento, en lógica consecuencia, del clero con una pensión y sueldo procedentes de las arcas del Estado. A los sacerdotes, especialmente a los procedentes de las órdenes religiosas, al depender la Iglesia cada vez más del Estado, además de elevarlos a la categoría de funcionarios del Estado, se les reducía en número para más adelante a todos los que se mostrasen en contra de las medidas del nuevo Estado, eliminarlos. Un proceso de esta envergadura se pudo llevar a término, practicando una cierta «tolerancia hacia los curas» y una «no tolerancia hacia los frailes» (Revuelta, 2007, p. 529). Los liberales no querían conventos, siempre difíciles de gobernar, sí parroquias y párrocos mucho más llevaderos y más ajustados a sus programas de transformación social. No olvidemos que, dentro de su esquema, todo se debía ajustar y acoplar con el sistema liberal.

Junto a los motivos políticos aparecieron razones de tipo demográfico eclesiástico: con las desamortizaciones y exclaustraciones se quería luchar contra el excesivo número de clérigos en España.

Estos dos motivos no deben ocultar el más real y concreto, a todas luces, el más importante: el económico. Para Revuelta «fue el motivo más poderoso». La exclaustración iba acompañada de la desamortización. En ella estaban interesados los teóricos del liberalismo económico, que no concebían una propiedad anquilosada en manos muertas; también lo estaban los negociantes y capitalistas, que veían en las exclaustraciones la posibilidad de comprar tierras baratas; y, por supuesto y no menos, lo estaban los políticos que esperaban ganar nuevos adeptos con la compra de bienes nacionales, así como los dirigentes de la Hacienda, que se prometían pingües recursos para enjugar la creciente deuda nacional. Era fácil en aquella coyuntura histórica de un país endeudado, apelar al bien común e incluso alentar promesas de felicidad en los campesinos desheredados. Al cabo, «como es sabido, quedó reforzada la clase burguesa y escamoteadas las promesas hechas a los proletarios. La desamortización sirvió de acicate eficacísimo al proceso exclaustrador, aunque por desgracia no realizó ni la reforma social ni el bien común» (Revuelta, 2005, p. 533).

A los tres motivos arriba enumerados habría que añadir otros mucho más difusos, pero cada vez más evidentes en la España y en la Europa de su 
tiempo como la siembra entre la opinión pública de la vinculación cierta y segura de los religiosos con los enemigos políticos de los liberales, independientemente de cómo se llamaran. Dicha vinculación hizo que con el paso del tiempo el binomio fraile-absolutismo se fuera imponiendo entre los españoles deseosos de cambio y amantes de revoluciones. De este esfuerzo propagandístico nacieron, entre otras cosas, la incomprensión, la falta de respeto y las campañas de difamación hacia los religiosos, hacia su estilo de vida y hacia el mantenimiento de sus votos religiosos, contrarios en su opinión y modo de vida a lo que los liberales suponían era la vida nueva y verdadera a la que todos los españoles debían aspirar. Los votos religiosos iban en contra de la libertad individual, elevada entonces a la categoría de mito. La vida religiosa y su subrayado comunitario era opuesta al espíritu individualista de la época. «El liberalismo tendía a debilitar o destruir los cuerpos orgánicos comunitarios». No se admitía el espíritu de cuerpo; se le consideraba como un quiste nocivo dentro del cuerpo social (Revuelta, 2007, pp. 531-532).

Explicadas las causas por las que la política exclaustradora pudo llevarse a cabo en España, Revuelta traza con mano maestra las tres etapas en las que se llevó a término la exclaustración y la desamortización y con ellas la práctica liquidación de la vida conventual y religiosa de la España preliberal.

La primera se corresponde con la etapa de la guerra de la independencia (1808-1814). Si durante este tiempo no se pudo llevar a cabo una reforma radical de las congregaciones religiosas, sí que se creó, en cambio, un precedente claro y evidente: «la existencia de las órdenes religiosas quedaba convertida en motivo de disensiones políticas». Con todo, a lo largo de este convulso y corto período se aprobaron una serie de medidas que marcaron el futuro: en diciembre de 1808 se decretó una exclaustración parcial; exclaustración que supuso la reducción de los conventos españoles a una tercera parte, la nacionalización de sus bienes y el favorecimiento y promoción de secularizaciones voluntarias con el pago de pensiones. Un año más tarde, agosto de 1809 , se procedió a una exclaustración general: quedaban suprimidas todas las órdenes sin excepción y se obligaba a los exclaustrados a dejar el hábito y a volver a los pueblos de su naturaleza, donde recibirían la pensión. Todos los bienes de los conventos quedaban aplicados a la nación. Estas medidas, rebajadas y muy condicionadas por muy diversas situaciones, fueron contempladas y en parte continuadas por las Cortes de Cádiz. En Cádiz no se determinó «la devolución condicional de los conventos, sino un restablecimiento restringido y provisional de los mismos hasta que las Cortes elaboraran una ley de reforma de regulares [...] La solución que adoptaron fue mantener las órdenes religiosas y restringir la devolución de los conventos cerrados hasta que se realizara una reforma profunda de 
aquéllas» (Revuelta, 2007, p. 535). El 25 de agosto de 1812 se ordenaba, en consecuencia, cerrar los conventos extinguidos por el gobierno intruso y tomar posesión de sus bienes.

La segunda etapa se dio durante el Trienio Constitucional (1820-1823). Durante este corto período se aprobaron una serie de decretos tajantes y contrarios a la presencia de religiosos dentro del territorio nacional. Por medio de la llamada ley de regulares, 1 de octubre de 1820, quedaban suprimidos todos los conventos de las órdenes monacales (benedictinos, cistercienses, jerónimos, cartujos y basilios), de los canónigos regulares (de San Agustín y premostratenses), hospitalarios y freires menores, de órdenes militares. Todos sus bienes pasaban al Estado y sus exclaustrados recibían una pensión, según su edad. Se cerraron 324 monasterios y conventos, todos ellos con patrimonios muy ricos. Las demás órdenes quedaban reformadas. La reforma consistía en el cierre de conventos que no tuvieran doce religiosos, así como los que no llegaran a 24 cuando había más de un convento de la misma orden en un mismo pueblo. A su vez, se prohibía la admisión de novicios, se facilitaba la secularización a todos aquellos que la pedían y se reconocía como única autoridad de los religiosos la de los obispos de las diócesis en las que estaban ubicadas sus casas religiosas. Todas estas medidas, para escarnio de los religiosos, se tomaron sin la autorización de la Santa Sede. Los resultados de tales medidas fueron espectaculares: en tan solo dos años se secularizaron 7.244 religiosos y 867 monjas. «La tercera parte de los religiosos españoles abandonó el claustro» (Revuelta, 1974, p. 61). A su vez, fruto de la desamortización que toda exclaustración comporta, se vendieron 25.177 fincas de los conventos extinguidos. Sus compradores fueron personas acomodadas, que, una vez dueños de estas fincas, no tuvieron inconveniente alguno en aumentar las rentas de sus nuevos colonos sin importarles las costumbres y los modos de proceder de sus anteriores dueños. Tras la caída del régimen liberal en 1823 se frenaron las reformas y se recuperaron, en parte, las ventas de fincas y de monasterios y conventos (Revuelta, 2007, pp. 535-537).

La tercera etapa, la que tuvo lugar entre 1834 y 1837 , fue la definitiva y la más tajante. Para las órdenes religiosas supuso «una muerte lenta y angustiosa» (Revuelta, 2007, p. 538). Durante estos tres años se vivió en España un «avance gradual del liberalismo hacia posiciones cada vez más radicales», lo que incidió muy negativamente en el orden y en la seguridad de las ciudades. Estos dos factores, unidos a la explosión de la primera guerra carlista, explican en parte las medidas que en contra de las órdenes religiosas se tomaran durante este tiempo y que acabaran «estableciendo en toda España la exclaustración total». El ocho de marzo de 1836, el gobierno Mendizábal ordenaba por medio de un decreto «el cierre de todas las casas religiosas 
de varones, con excepción de los tres colegios de misioneros de Ultramar, escolapios y hospitalarios. Se suprimían los conventos de religiosas que no llegaran a 20 (lo que obligaba a la reunión de sus comunidades), pero en cualquier caso sus bienes eran nacionalizados. Este decreto fue elevado al rango de ley el 29 de julio de 1837» (Revuelta, 2007, pp. 537-539).

Finalmente, a estas leyes exclaustradoras deben sumarse los decretos y leyes nacidos con la Revolución de 1868. Con el decreto del 1 de enero de 1869 «se incautaban todos los archivos, bibliotecas, gabinetes y demás colecciones de objetos de ciencia, arte o literatura, que con cualquier nombre estén hoy a cargo de las Catedrales, Cabildos, Monasterios y Órdenes militares. Esta riqueza, se añadía, será considerada como nacional y puesta al servicio público, en cuanto se clasifiquen, en las bibliotecas, archivos y museos nacionales». Con esta ley, tal como se decía en su largo preámbulo, se consumaba el proceso desamortizador y secularizador de los gobiernos liberales en España (Revuelta, 2017, pp. 169-170). Con estas medidas, por supuestas razones de bien común, se daba un gran paso hacia lo que se ha llamado la «la secularización» de los bienes culturales (Revuelta, 2017, pp. 170-171). Los obispos, como parece natural, se opusieron a estas medidas; las consideraban injustas, contrarias al derecho de propiedad, opuestas al Concordato y la legislación civil y canónica vigentes. Al tiempo que afirmaban su derecho de propiedad no callaban que ellos eran los responsables de su custodia. Con la llegada de la Restauración borbónica una de las primeras medidas fue la derogación de este decreto de incautación y el cierre casi definitivo del proceso exclaustrador (Revuelta, 2017, p. 184).

¿Qué conclusiones deben sacarse del proceso legislativo exclaustrador? La primera que exclaustración y desamortización iban unidas; la segunda y más importante que millares de religiosos y religiosas, expulsados de sus casas y conventos, comenzaron a vivir una tragedia personal para la que nada habían hecho (Revuelta, 1978, p. 47). Una tragedia, matiza Revuelta, en la que los regulares, personas observadoras y conocedoras de la realidad exterior, apreciaron con disgusto «el contraste... entre el interés y meticulosidad con que se llevó a cabo la desamortización de los bienes conventuales y la incuria, la improvisación y las vacilaciones, que descuidaron y retardaron el pago de las pensiones». El binomio desamortización--exclaustración se decantaba en perjuicio de los regulares. Todos ellos sufrieron una política inhumana, "fruto, si no de mala fe, sí al menos de un desinterés reprobable hacia unos ciudadanos, a los que con tanto denuedo se había arrojado de sus mansiones y despojado de los medios de subsistencia». Una política inhumana a la que contribuyeron de manera manifiesta el confusionismo, la improvisación y la parsimoniosa ejecución del pago que de sus pensiones en 
justicia se les debía hacer. Inmediatamente después de los decretos desamortizadores se instaló entre los religiosos exclaustrados un clima de confusión; clima que los llevó en la mayoría de los casos a no saber a quién dirigirse ni qué hacer a la hora del cobro de sus cada vez más inciertas pensiones. Confusionismo que propició, excepto en algunas provincias, que el puntual pago de sus pensiones no se abonase a los exclaustrados en la mayoría de las provincias. Si el sistema de pago del decreto del 8 de marzo de 1836 le suponía a la Hacienda pública española un desembolso de 68 millones de reales, «la undécima parte del presupuesto nacional de 1835» (Revuelta, 1978, pp. 47-50), lo más normal era que este alto caudal monetario tardara en llegar a quienes iba destinado, como así fue.

Al confusionismo e improvisación a la hora de recibir sus justas pensiones, súmesele la desconfianza que los pagadores de las pensiones, muchos de ellos personas poco adictas a los religiosos, causaban en el ánimo de los exclaustrados. Desde junio de 1836, los administradores de las pensiones no fueron los miembros de las juntas diocesanas, protectoras de los regulares, sino un conjunto de comisionados personalmente poco adictos a los frailes y distraídos en otros encargos y obligaciones, que para más sufrimiento de los antiguos religiosos y división y enemistad del clero español, se vieron en la obligación de echar mano de los subsidios del clero al Estado, unos veinte millones de reales, dejando a los sacerdotes seculares sin los recursos necesarios para el pago de sus sueldos y pensiones. Inicialmente y durante un tiempo, el dinero que tenía que ir destinado a los sacerdotes seculares, lo fue a los exclaustrados. En definitiva, la Iglesia de España se vio en la obligación de contribuir al pago de las pensiones de los exclaustrados con una serie de arbitrios de pago, hasta doce, destinados a remediar casos extremos e imprevistos. Nada, en realidad, se podía hacer en tiempos tan calamitosos. Todos los recursos que la Hacienda pudiese recaudar en 1836-1837 tenían un único destino: pagar la guerra y terminar de implantar en todo el territorio nacional el sistema liberal (Revuelta, 1978, pp. 53-55).

Aun cuando los exclaustrados, al ser suprimidos las juntas y los comisionados que les tenían que pagar sus pensiones, quedaron englobados entre las clases pasivas pagadas por el Estado, las cantidades destinadas al pago de sus pensiones entre 1838-1841, brillaron "por su ausencia en los presupuestos de gastos del Estado». Con todo, a partir de 1842 se fijó «una cantidad determinada en el presupuesto de clases pasivas, a favor de los exclaustrados y monjas», expediente que no dio los frutos esperados y que hizo que durante la regencia de Espartero «los exclaustrados y las monjas padecieron un olvido sistemático». A la altura de 1843 muchos exclaustrados residentes en Valencia y Barcelona reclamaban que llevaban «siete años y diez meses sin 
cobrar» y todavía más los de Sevilla que llegaron a los 103 meses sin cobrar pensión alguna. A todos ellos, el Gobierno les daba la categoría de difuntos (Revuelta, 1978, pp. 67-72). En lo referente a las monjas, su situación llegó a ser tan extrema y calamitosa que juntas de señoras caritativas salieron a las calles para pedir limosnas y donativos en su favor. Situación que le hizo afirmar a Ayllón, ministro de Hacienda del gobierno de Joaquín María López, que la suerte de las religiosas había sido la más desgraciada, viéndose unas para no perecer "precisadas a impetrar la caridad pública» y otras a abrir suscripciones voluntarias en la corte y otras ciudades para poder mantenerse (Revuelta, 1978, p. 72).

En suma y como expresión gráfica y concreta de cuanto estamos describiendo, un nuevo grupo de marginados y excluidos nacía en la España liberal: el de los exclaustrados. Como tales, tanto en particular como colectivamente, sufrieron grandes tribulaciones y peligros. La más ignominiosa y perturbadora, aparte de su exclusión social, fue la pérdida de su identidad religiosa y, por lo tanto, personal. Los antiguos religiosos, ahora todos ellos exclaustrados, salían de sus conventos «como alimañas acosadas, caminando de noche, ocultándose en los bosques y temiendo por su vida, llenos de hambre y de frío. Con la dispersión, a cada exclaustrado, a partir del 8 de marzo de 1836, le tocó vivir su propia historia. Algunos, afirmaba el obispo de Coria, no comieron nada durante tres días seguidos. Vivían indigentemente. No recibían pensión alguna. «Ancianos, enfermos, desvalidos, desesperados, gritaban los responsables de la Junta diocesana de Sevilla, y en peligro de entregarse a los mayores excesos, vagan muchos en la desnudez, faltos de todo lo necesario para vivir». El comportamiento del Gobierno no podía ser más injusto; el obispo de Canarias, Judas José Romo, no lograba entender que la Caja de Amortización recaudase los cuantiosos productos de los conventos, mientras los exclaustrados, sus antiguos y legítimos dueños, «pordiosean por las calles, no obstante el derecho preferente que les asiste a ser alimentados con los réditos de los mismos bienes y el pacto solemne que con ellos ha hecho V. M. de proveer pronta y eficazmente a todos en sus necesidades» (Revuelta, 1980, pp. 324-325).

A tal cúmulo de desdichas exteriores, deben sumarse, pese a que las leyes civiles no entraban en ello, las interiores. Muchos exclaustrados estaban convencidos «de que la exclaustración no alteraba en nada su condición de religiosos» y que sus votos religiosos seguían vigentes. La mayoría de ellos, pues, siguieron considerándose religiosos y como tales trataron de seguir viviendo como si fuesen frailes y estuvieran «en sus conventos». El Papa, por su parte, trató de mantener la jurisdicción de los religiosos que le era privativa, bien por la vía de los comisarios, bien por la vía de los obispos, a 
quienes sí reconocían los liberales. De esta manera, «la jurisdicción de los regulares quedaba por tanto firmemente conservada». Únicamente se aflojó en lo referente al voto de pobreza: ante el alargamiento de la exclaustración se les concedió la facultad de admitir peculios y pensiones, ser propietarios y testar a favor de la orden o de familias e individuos pobres (Revuelta, 1989, pp. 331-334).

Dentro del grupo marginal que a estas alturas ya eran los exclaustrados, los peormente posicionados fueron los coristas y los legos: 5.641 los primeros y 5.763 los segundos, al comenzar la exclaustración. Los coristas eran estudiantes y aspirantes al sacerdocio; los legos eran hermanos seglares con votos. Ambos grupos, por el hecho de ser religiosos, habían hecho voto de castidad. Uno de los primeros problemas que tuvieron que superar fue el del cobro de sus pensiones; unos y otros vieron reducido muy considerablemente el tiempo de cobranza de sus pensiones a dos años. El gobierno no estaba dispuesto a pagar a jóvenes ni a personas capacitadas para el trabajo. Mayor problema es el que les afectó a los coristas con votos. Estos tenían un doble problema: si querían casarse tenían que renunciar al voto de castidad, algo muy difícil en aquellos momentos y que dependía de la Santa Sede, no siempre dispuesta a concederlo. Al no conseguirlo, no se podían casar legalmente ya que el matrimonio en España era canónico y no civil. A este problema se añadía otro: el gobierno mantuvo la prohibición de nuevas órdenes sacerdotales entre 1835 y 1844. Si se querían ordenar no tenían más remedio que emigrar al extranjero. Para los exclaustrados, afirma irónicamente Revuelta en uno de sus primeros escritos, no pareció en ningún momento haber pacto de Vergara (Revuelta, 1974, p. 86).

Ante tan dramática situación, los políticos de la época trataron para paliar las trágicas consecuencias de la legislación exclaustradora colocar a los 31.000 exclaustrados al servicio de obispos benévolos que los quisiesen acoger en sus diócesis. Al final, una buena parte de este nuevo grupo de marginados acabó sirviendo como ecónomo interino en las parroquias de todas las diócesis de España. Sin embargo, esta colocación, por itinerante e interina, no fue suficiente para todos ellos ${ }^{4}$. No les satisfacía. La inmensa mayoría «mantuvieron un espíritu de clase dentro del clero y un cariño especial hacia su antigua vida conventual». Aún con esta nostalgia y melancolía como fondo, «su presencia al servicio de la Iglesia española fue notable, y el influjo en que en ella dejaron en el campo pastoral o en el terreno ideológico está por estudiar» (Revuelta, 1980, p. 349).

4 Estamos hablando de un colectivo que, aunque menguó, siempre fue numeroso: en 1835 eran 30.906, en 1837 eran 23.935 y en 1854 habían bajado a 8.341. 
Además de los coristas y legos, otro de los grupos más castigados fue el de las monjas, el de las religiosas. A ellas, tal vez por ser mujeres y por presentar inicialmente menos inconvenientes que los hombres a la hora de sumarlos al proyecto que los liberales querían para la nueva España, no se les aplicó la supresión general. En su caso, «hubo una reforma, pero no supresión» ni extinción total. A las monjas se les aplicó una política que a la larga pretendía lo mismo: eso sí, ejecutada por consunción lenta. Aunque sus bienes, como los de los religiosos, fueron aplicados a la Caja de amortización, se les permitió, rebajando el contenido de la orden del 8 de marzo, mantener abiertos algunos de los conventos que no llegaban al número exigido, veinte religiosas, para poder continuar existiendo. Igualmente, a las religiosas profesas, por el artículo 9 de la ley de 9 de julio de 1837, se les permitía «continuar en el género de vida que habían abrazado». A cambio, para acabar con ellas, no se admitían novicias ni nuevas profesiones y las superioras debían ser elegidas por la comunidad y las autoridades civiles podían proceder a las exclaustraciones voluntarias. Todos sus bienes pasaban a ser bienes nacionales. En síntesis, la reforma de las monjas consistió en la reunión de distintas comunidades de una misma ciudad o de una misma región en algunos conventos y en la incautación de sus bienes. En lo referente a la reunión, triunfó el criterio de los liberales moderados, mientras en la desamortización se impuso el criterio de los progresistas. Al final, la fallida reunión en distintos conventos, así como la prohibición en la admisión de novicias y las facilidades a las exclaustraciones voluntarias llevaron a las comunidades religiosas femeninas a una desaparición progresiva, que se logró frenar a partir de 1838; eso sí, sin admitir novicia alguna hasta 1852 (Revuelta, 1981, p. 429).

En suma y como síntesis, con la exclaustración, aplicada sin excepciones «sin ponderar las diferencias ni consultar a los pueblos afectados» (Revuelta, 2007, p. 530), se dejaba «sin reconocimiento legal al sector más independiente y compacto de la clerecía española, que quedaba reducida a párrocos y obispos controlables» (Revuelta, 1985, p. 15). Se prefirió la exclaustración total a la parcial, con la injusticia que ello comportaba. Se justificaba «como una medida de salud pública para bien de la Iglesia y el Estado, a quienes nada servían aquellos envejecidos y degenerados institutos» (Revuelta, 2007, p. 532). Los resultados, repetimos como se indica en las conclusiones de Motivaciones y desarrollo de la exclaustración del siglo XIX, fueron bastante tristes: pérdidas de monumentos y tesoros artísticos. Humillación y sufrimiento de muchas personas inocentes, desamortización sin sentido social, fracaso de todo intento de convivencia, fomento de la ideología antiliberal en los eclesiásticos. Los métodos empleados fueron reprobables y muy poco liberales, pues se actuó casi siempre con intolerancia, improvisación y desproporción 
y, a veces con crueldad y violencia. La Iglesia quedó muy traumatizada con estos golpes que la impulsaban a cerrarse más y más sobre sí misma y a desconfiar de las conquistas y postulados de los movimientos liberales y democráticos. La cuestión de las órdenes religiosas aparece ligada a la división política de España que caracteriza nuestra historia contemporánea.

Todo cuanto con ánimo de síntesis hemos escrito, quedaba años antes analizado, relatado y sopesado en uno de los libros de los que el Padre Revuelta se sintió más satisfecho: La Exclaustración (1833-1840), editado en Madrid en 1976 por la Biblioteca de Autores Cristianos. Así nos lo presenta y valora en sus Memorias: "Con los fondos consultados en la tesis (sobre todo en AHN, sección Consejos) me lancé a escribir el libro de La exclaustración, resaltando no tanto la desamortización, de la que se hicieron entonces muchos trabajos, sino un hecho más doloroso para la Iglesia, que fue la supresión total de todas las congregaciones religiosas con la supresión de sus conventos. El libro se publicó en 1976, y como el anterior se agotó pronto. Pero no fue la BAC sino en CEU Ediciones, el que lo reeditó en 2010, con ligeras variantes. En el prólogo de esta segunda edición recuerdo la buena acogida de la obra, como lo de muestran las casi treinta recensiones de las que tenemos noticia. Todavía hoy sigue siendo una obra de referencia obligada en los trabajos históricos sobre la política religiosa del siglo XIX y sobre la vida de las órdenes religiosas españolas y sus conventos. [...]. Los recensores, en general, se mostraron muy generosos con nuestro libro. Dijeron que era una obra fundamental e imprescindible. Se la presentaba como obra profunda, comprensiva, crítica, aleccionadora y amena; escrita con sinceridad y emoción, con valentía y rigor. Se elogiaba el orden con el que se había domesticado un material bravío, y el mérito de haber ofrecido una visión de conjunto sobre un tema que antes se había tratado de manera dispersa. Todos elogiaban su rigor científico, basado en una documentación en buena parte inédita. Y muchos extendían sus elogios a la agilidad del estilo y la viveza de la narración, a la manera de un gran reportaje. En una recensión se asegura que «el libro se lee como una novela». Pero en todo hay excepciones que confirman la regla, y el libro fue criticado, por la manera de interpretar la matanza de frailes, por Josep Fontana y Antonio Fernández» (Revuelta, 2019, pp. 94-95)

Pero por muy dramáticas y generales que fueran las consecuencias de la exclaustración y desamortización, gracias «a la constancia con que las monjas se aferraron a sus claustros, a la entereza con que soportaron el hambre y la miseria a lo largo de diez años, a la esperanza, en fin, con que afrontaron la amenaza de la extinción biológica de sus comunidades» y gracias a «la profunda y sincera fe religiosa» de los exclaustrados como colectivo, uno «de 
los más puros y sinceros de nuestro siglo XIX» (Revuelta, 1981, p. 431 y 1974, p. 86), pudo mantenerse el ascua bajo las cenizas (Revuelta, 2007, p. 541). Pasado un tiempo y llegada una nueva coyuntura de más paz, cordialidad y racionalidad, los religiosos y las religiosas, los frailes y las monjas, renacieron en la España contemporánea.

\title{
4. MANUEL REVUELTA GONZÁLEZ, PROMOTOR DE LOS ESTUDIOS SOBRE LA RESTAURACIÓN Y RESTABLECIMIENTO DE LA VIDA RELIGIOSA
}

\begin{abstract}
«El restablecimiento de las congregaciones religiosa es el acontecimiento más llamativo en la renovación del catolicismo español durante el último cuarto del siglo XIX». (Revuelta, 2002, p. 74)
\end{abstract}

Hasta aquí lo correspondiente a la exclaustración y los exclaustrados. Hasta aquí una de las fases más productivas y brillantes de la carrera de Revuelta como historiador. Sin embargo, al religioso Revuelta y al estudioso de la vida religiosa no le bastaba con acompañar el dolor de sus amigos, los exclaustrados. Años más tarde, en la medida de sus fuerzas, aunque con menos amplitud y dedicación, abordó el complejo y estimulante tema de la restauración de las congregaciones religiosas en la España del siglo XIX (Revuelta, 2013) y de su presencia en la España del siglo XX. Esfuerzo que le llevó a afirmar en una obra de síntesis que: «el restablecimiento de las congregaciones religiosas es el acontecimiento más llamativo en la renovación del catolicismo español durante el último cuarto del siglo XIX» (Revuelta, 2002, p. 74). Como muestra de afirmación tan excesiva para un historiador tan juicioso y ponderado como fue Revuelta, ahí quedan sus trabajos sobre la Compañía de Jesús y sus variadas contribuciones sobre la vida religiosa, especialmente la apostólica, en la España contemporánea.

En este nuevo paso, le guiaron e inspiraron la cordura y el deseo de ver encarnada, tal como lo percibía su admirado Balmes, la nueva vida religiosa y sacerdotal en el nuevo marco que el liberalismo, para bien y para mal de la Iglesia, había traído definitivamente. «El rescoldo de la llama bajo las cenizas» (Revuelta, 2010, p. 32), dirá en otro lugar, será la luminaria que orientará su buen hacer en beneficio directo de sus amigos, los religiosos, e indirecto del sencillo pueblo católico español. Para Revuelta este nuevo 
cometido no solo era cuestión de oficio, era también cuestión de agradecimiento y no menos de fe.

Será desde esta perspectiva desde la que Revuelta se mostrará, ya lo decíamos al principio, cercano a personas de todas las familias religiosas, especialmente, a las de los fundadores y fundadoras de las nuevas congregaciones femeninas españolas de la segunda mitad del siglo XIX. A las fundadoras las califica de "figuras encantadoras», entre las que sitúa a mujeres de la categoría de Paula Montal, María Teresa Jornet, Rafaela Porras, María Josefa Cipitria... Isabel de Mornages, Pabla Bescós (Revuelta, 2002, p. 77). Guiado por el agradecimiento y la admiración hacia estas ricas y complejas personalidades, así como hacia sus seguidores, Revuelta se esforzará por mostrarnos los esfuerzos que estas falanges hicieron para que «la vida de la Iglesia», estuviese de nuevo y a ser posible para siempre animada por grupos de «comprometidos con sus votos religiosos en un servicio radical a la comunidad cristiana, siguiendo las formas de vida o carismas de sus institutos» (Revuelta, 2004, p. 271). Los nuevos representantes de la vida religiosa, muchos de ellos figuras carismáticas, con la ayuda de la Iglesia y con la fuerza de los nuevos creyentes, vencieron los graves y pesados inconvenientes que el anticlericalismo y antimonasticismo trataron de ponerles. A todos ellos, así como a sus miles de seguidores se debe el que en la última etapa de nuestra historia contemporánea nacional la trayectoria y «la importancia de las órdenes y congregaciones religiosas no hayan sido menores que en las épocas precedentes. Una vez más se cumple la paradoja de que, en la época más secularizada de nuestra historia, la acción de los religiosos adquiere un significado relevante, aunque sólo sea por los odios o fervores que suscitaron unas instituciones que ejercieron una acción muy influyente en la historia política, social, cultural y educativa de España en los dos últimos siglos» (Revuelta, 2004, p. 273).

Sin que Revuelta pueda ser considerado, como lo es el tema de la exclaustración, uno de los máximos especialistas españoles, sí que a su modo ha marcado el rumbo de los estudios sobre la restauración de la vida de las congregaciones y órdenes religiosas en España. Ahí queda, solo esbozado, el intento de periodización histórica de las congregaciones religiosas españolas. Aquí, como es frecuente en toda su trayectoria y en todos los nuevos temas que aborda, toma como criterio el clima y el ambiente políticos y sociales en los que cada uno de estos períodos se consumó.

El resultado de este intento son las siguientes seis etapas. La primera se inicia durante la liquidación del Antiguo Régimen y finaliza con la exclaustración definitiva (1808-1837). Es un período, recapitula Revuelta, muy importante y el mejor estudiado hasta el momento (Revuelta, 2004, p. 276). 
La segunda se corresponde con el período intermedio de la dispersión de los exclaustrados y de las restauraciones aisladas permitidas por el Concordato de 1851; en los estudios publicados de esta etapa se destaca la importancia que tuvieron los exclaustrados a la hora de la conservación del espíritu restauracionista (Revuelta, 2004, p. 277). La tercera etapa, la de la plenitud de la restauración de las congregaciones religiosas (1875-1931), coincide con el período de la recuperación de la Iglesia española (Revuelta, 1991). Los religiosos, como muestra de su recuperación y de su nueva y creativa presencia en la España de la época, formarán una tupida red de comunidades, colegios, iglesias, templos, santuarios, obras sociales, editoriales, centros asistenciales, que suscitará la acrimonia, el rechazo y hasta el ataque de la España anticlerical (Revuelta, 2002) y más adelante laica. Esta tercera etapa es por la fuerza de los hechos, por una parte, gloriosa y triunfalista, y por otra, conflictiva y polémica. Durante este tiempo, aprovechando la coyuntura exterior y la recuperación total de todas las congregaciones religiosas, las congregaciones religiosas españolas se hicieron más universales, libres y misioneras. Los religiosos españoles tomaron conciencia de su universalidad y en no pocas ocasiones lideraron sus respectivas congregaciones con cargos tan relevantes como Superiores Generales y consejeros de todo orden. Además, durante esta etapa nacieron y crecieron numerosas congregaciones religiosas, que atendieron y sirvieron a todo tipo de ministerios en favor del pueblo cristiano y de la sociedad española (Revuelta, 2004, pp. 278-279). La cuarta está muy relacionada con la crisis de la persecución de la II República y de la Guerra española (1931-1939); tiempo de paréntesis del que todavía no se sabe mucho (Revuelta, 2004, pp. 279-280). La quinta tiene que ver con la restauración bajo el régimen de Franco (1940-1960). Un restauracionismo triunfal durante los primeros años, que lentamente se va enriqueciendo con un fuerte deseo en la mayor parte de las congregaciones religiosas de servicio y acercamiento a las clases populares y a los sectores marginados. «Son años de autocrítica y de despertar de la conciencia social en los sectores eclesiásticos en general y en los religiosos en particular». Tiempos y circunstancias sobre las que hay todavía un gran vacío historiográfico (Revuelta, 2004, p. 280) y, finalmente, la sexta etapa, etapa de renovación y crisis; se inicia al comienzo de los años 1960 y continúa presente entre nosotros. «Los estudios históricos que reflejan las crisis y las innovaciones de los últimos decenios son más bien escasos, a menudo sesgados por emociones vivenciales, y, a veces, muy marcados por la polémica» (Revuelta, 2004, p. 281).

Amén de su periodización, Revuelta se atreve a ofrecerle al futuro historiador de la vida religiosa española una serie de consejos: no deberá conformarse con presentarnos la vida externa de las congregaciones religiosos, 
tendrá que penetrar en su vida interna para los que necesitará acopiar y elaborar estadísticas de los ingresos, abandonos y perseverancia de los religiosos y sobre todo tendrá que estudiar y sintonizar con la espiritualidad de las distintas congregaciones, «aspecto muy importante, porque es lo que caracteriza y distingue a cada congregación religiosa»; no deberá olvidarse de la formación de los jóvenes y de las costumbres de cada grupo religioso. No echará en saco roto todo lo concerniente a su economía y a su manera de entender y vivir la pobreza y sobre todo tratará de reconstruir por dentro y por fuera sus ministerios espirituales y pastorales: ejercicios espirituales y misiones populares, predicación y propagación de la Palabra de Dios por medio de la palabra escrita y más tarde por medio de la Prensa y de las editoriales, sin olvidarse de la enseñanza y de la divulgación de la cultura, su «ministerio más decisivo y discutido y también el mejor estudiado» y de los llamados ministerios asistenciales, llevados a cabo por numerosas congregaciones femeninas y por algunas masculinas especializadas en ello; tendrá, finalmente, en cuenta el significado y la importancia de las misiones exteriores y la evangelización de los nuevos mundos. Por último, dará cuenta del esfuerzo de las congregaciones religiosas en la promoción y el trabajo con todo tipo de asociaciones (Revuelta, 2004, pp. 282-284).

Todas estas recomendaciones y consejos trató de llevarlos a término en una de sus últimas colaboraciones sobre el particular, concretamente en un artículo ya de muy última hora: Las órdenes religiosas en la España del siglo XX, (Revuelta, 2014) publicado en la obra colectiva editada por J. A. Escudero, La Iglesia en la historia de España, Marcial Pons: Madrid 2014, 1197-2010 y recogido en el capítulo 10 de su Enigmas históricos de la Iglesia española contemporánea (Revuelta, 2017). En estas páginas se intenta hacer un estudio-presentación de lo más señero de la historia de las órdenes religiosas en la España contemporánea.

El número total de religiosos al comienzo del siglo XX (año 1900) en España alcanzaba la no desdeñable cifra de 54.738, de ellos 12.142 eran religiosos y 42.596 religiosas; al final, año 1930, el número total se había notablemente incrementado, alcanzando los 81.142: 20.467 religiosos y 60.695 religiosas. De estos números deben sacarse algunas consecuencias: las antiguas monjas, por la fuerza de clausura, se habían transformado en religiosas de vida activa. Los religiosos se establecieron principalmente en las ciudades y capitales de las regiones más prósperas. Nadie los podía calificar de dedicarse a actividades improductivas y de ser una carga, por su ociosidad, para la sociedad. Sus actividades tenían, por otra parte, «un gran impacto en los comportamientos y mentalidades de la sociedad», tal como puede percibirse en la respuesta del pueblo sencillo en el desarrollo de las 
misiones populares y en la incidencia de las publicaciones periódicas de sus revistas —en 1907, 54 publicaciones dirigidas por los religiosos mantenían la fe ilustrada del pueblo-, sin olvidarse del influjo de los sindicatos católicos en el mundo obrero y en el movimiento sindical. Pero donde más se dejaba notar su influencia era en el mundo de la enseñanza, «el ochenta por ciento de la segunda enseñanza estaba a principios de siglo en manos de la Iglesia, especialmente a cargo de los religiosos» y de las religiosas. Otra de las consecuencias fue que durante este tiempo mucho más que en etapas anteriores todas las congregaciones religiosas, muy en contacto con lo que cada congregación en particular era o representaba y con los problemas particulares y generales que todas ellas padecían, acrecentaron su espíritu internacional y su carácter universal, haciéndose realmente independientes y recobrando su carisma a todos los niveles (Revuelta, 2017, pp. 259-260).

El constante y sostenido crecimiento de las congregaciones religiosas "suscitó el entusiasmo de los católicos y el enojo de los anticlericales». Políticos como Pi y Margall decían que los religiosos por ser hombres y mujeres que se apartan del trabajo, «lejos de poder ser considerados como personas virtuosas, se las puede considerar como personas egoístas que no tienen virtud de ninguna clase». A nadie le puede extrañar que contra sus propias personas, sus domicilios e instituciones fueron frecuentes las movilizaciones y asaltos en las grandes ciudades tal como sucedió en Madrid en 1901 y en Barcelona en 1909, lo que propició una cierta actividad legislativa que tenía como objetivo fundamental limitar el número de congregaciones religiosas, así como incluirlas dentro de una nueva ley de asociaciones, lógica por otra parte, que no se llegó a aprobar. En lo referente a su estilo de vida, pese a un cambio en muchas de sus actividades, su vida y costumbres «se acomodaban a las pautas tradicionales: observancia estricta de las reglas, intensa vida de piedad, distribución del tiempo, aislamiento del exterior, trabajo regulado y obediencia estricta» (Revuelta, 2017, pp. 260-262).

Durante la segunda etapa, la correspondiente a la Segunda República y la Guerra Civil (1931-1936), se produjo un cese de las fundaciones y una paralización de trabajos, actividades y ministerios. La vida religiosa continúo ralentizada, pero no parada; se vivió con fervor y fidelidad. Durante la Guerra se impuso «la gran dispersión, el camuflaje, el disfraz y el culto a escondidas [...] Las tribulaciones sufridas les pusieron al lado de los vencedores que desde el principio les favorecieron» (Revuelta, 2017, pp. 262-264).

Tercera etapa: recuperación y apogeo (1939-1965). Después de la Guerra se realizó, sin apenas ruptura con relación a la restauración anterior, la segunda gran restauración; una «restauración continuada sobre estructuras 
anteriores». Muy pronto se recuperó la normalidad. La legislación les favoreció y veló por ellos: el 3 de mayo de 1938 se restablecía por decreto la Compañía de Jesús: el 2 de febrero de 1939 por ley se derogaba la ley de confesiones y congregaciones religiosas, lo que unido a la ley del 20 de septiembre de 1938 por la que se reafirmaba la confesionalidad católica de la enseñanza, ponía en el centro de la vida nacional a la vida religiosa. A mediados de los años cincuenta hubo un ligero cambio y los religiosos, sin dejar de cumplir con sus obligaciones y sin romper con su estilo de vida, se fueron inclinando hacia la atención de las clases populares. Entre tanto, la vida religiosa continúo creciendo: en 1963 los religiosos de vida activa, incluidos los misioneros que trabajaban fuera de España, 36.621. En 1968, 32.820. Las religiosas de vida activa eran en 1963, incluidas las misioneras, 76.401; cinco años después, en 1968, eran 94.188. Si añadimos el número de religiosas contemplativas y el número de contemplativos, incluidos los misioneros, «en vísperas del Concilio el número de religiosos españoles ronda los 150.000». Un número tan elevado era fruto de la suma de las congregaciones históricas y de los 48 nuevos institutos religiosos que se fundaron en España entre 1939 y 1958. Durante esta etapa, cosa que no había sucedido en épocas anteriores, los religiosos se dotaron de una institución, la CONFER, que velaba por sus intereses y por su presencia en una nueva sociedad. La fecha de su fundación fue el año 1953; los mismos religiosos, especialmente los dedicados a la enseñanza, se agruparon por parecidas razones en la FERE el año 1957 (Revuelta, 2017, pp. 264-268).

Finalmente, Revuelta nos presenta la cuarta etapa, la denomina: la etapa de renovación y crisis postconciliar (1965-1999). Lo más visible y tangible en medio de un cambio de época propiciado en gran parte por la celebración y recepción del Concilio Vaticano II, además de una readaptación no del todo lograda de la vida religiosa a los nuevos tiempos, fue y sigue siendo la disminución en el número de religiosos. «El número de los religiosos se ha reducido a la mitad». Tal vez en esta dramática disminución haya podido contribuir la competencia creada a la vida religiosa por «los institutos seculares y los movimientos apostólicos han creado una notable competencia a los institutos religiosos». Con todo, a finales del siglo XX existían en España 320 institutos religiosos (97 masculinos y 223 femeninos), con un número aproximado de 13.000 religiosos y 54.000 religiosas residentes en España... sus servicios seguían siendo muy estimados, "por su valor testimonial, educativo y social» (Revuelta, 2017, pp. 270-272). 


\section{CONCLUSIÓN}

La apuesta del profesor Revuelta González por la vida religiosa es más que clara. Su vocación religiosa y sus querencias cristianas y castellanas por la sencillez, por la entrega generosa de la vida por causas divinas y humanas, además de sus anhelos de justicia por un grupo de excluidos por razones exclusivamente políticas y económicas, los exclaustrados, le convirtieron con el paso de los años en uno de los principales especialistas no solo de la vida religiosa en cuanto tal, sino de la vida de los católicos y de su Iglesia en la convulsa España de los siglos XIX y XX.

Más allá de este indiscutido logro, nos tenemos que preguntar para deshacer entuertos y sospechas qué factores se conjuntaron en la trayectoria historiográfica del Padre Revuelta para que al final de su vida, podamos considerarlo con toda justicia como uno de los grandes historiadores españoles de las últimas décadas.

En mi opinión son tres: el contenido y estilo de sus obras; su engranaje con la historia contemporánea de España y los mensajes y reflexiones que suscita en los lectores.

Contenido y estilo de sus obras: quien tenga la suerte de acercarse a uno cualquiera de los cerca de quinientos títulos firmados por Revuelta, apreciará desde el primer momento un orden y una estructura, siempre muy pedagógicos, que le harán no perderse en la lectura, corta o larga, del texto que lea o estudie. Además de no perderse, experimentará desde el primer momento que con Revuelta siempre se aprende y casi nunca se discute, porque sus tesis y objetivos están bien construidos, científica e historiográficamente bien argumentados y, sobre todo, porque de por sí, es decir por el buen hacer de quien los ha escrito, resultan convincentes. Argumentación convincente y en nada asfixiante, estilo sencillo, ágil, jugoso y lleno de vida, hacen que con Revuelta se aprenda sin fatiga y lo que es más importante que una segunda o tercera lectura resulte como nueva.

En casi ninguna de sus obras, habla o emplea Revuelta una palabra muy en boga con toda razón entre los historiadores de hoy: el contexto, la contextualización. Para Revuelta, es mi opinión, el contexto es lo que él denomina en algunos de los pasajes de sus memorias en los que analiza y juzga su obra: el engranaje. El engranaje, en el caso concreto de la historia de la vida religiosa y también de todos los temas por él estudiados, con la historia contemporánea de España. El engranaje le ayuda a contextualizar, a situar y a entender cuanto estudia en el fiel justo de la balanza; le evita ser extemporáneo, le conduce por caminos seguros, le permite dialogar con el tiempo y con los estudiosos del momento, le faculta para entender lo que estudia en 
su justa medida y, finalmente, el engranaje le ofrece una panorámica general y al mismo tiempo concreta para leer lo analizado con precisión y altura de miras.

A nadie, pues, le debe extrañar que su obra, en general, y sus cientos de títulos, susciten en todos los que le leen mensajes y reflexiones por las que el lector se apropia personalmente del trabajo del historiador y de modo pacífico, nunca inducido, saca sus propias conclusiones.

Las conclusiones que de la dedicación, entusiasmo y buen hacer de Revuelta como historiador de la vida religiosa en la España contemporánea de los siglos XIX y XX, que nosotros hemos sacado, nos han hecho valorar todavía más si cabe la vida religiosa en cuanto tal, nos han permitido apreciar y sopesar la graves injusticias y desafueros que se cometieron con un no pequeño grupo de personas que por fidelidad a su vocación pagaron los desafueros políticos y sociales de los responsables del orden público de su tiempo y, finalmente, nos han ayudado a valorar la vitalidad de la vida religiosa. Capaz no solo de renacer de las ascuas en las que medio languidecían en las décadas centrales del siglo XIX, sino de constituirse en un colectivo, casi siempre criticado y no comprendido, fiel a su vocación y digno colaborador del progreso espiritual y de la paz social, política y económica de la España de los siglos XX y XXI.

\section{REFERENCIAS}

Fernández, L. (1981). Historia del Colegio de San José de Valladolid (1881-1981). Valladolid: Colegio san José.

Moliner, A. (2000). Félix Sardá i Salvany y el integrismo en la Restauración. Barcelona: Universidad Autónoma.

Ortega, J. L. (2000). Felicidades, Jesucristo. Madrid: Biblioteca de Autores Cristianos.

Revuelta, M. (1974). Los conventos de Vizcaya durante la primera guerra carlista. Letras de Deusto, 7, 53-86.

Revuelta, M. (1978). Los pagos de pensiones a los exclaustrados y a las monjas (18351840). Estudios Eclesiásticos, 53, 47-76.

Revuelta, M. (1980). Vicisitudes y colocaciones de un grupo social marginado: los exclaustrados del siglo XIX. Hispania Sacra, 32, 323-351.

Revuelta, M. (1981). La reunión de los conventos de monjas y la incautación de sus bienes (1836-1838). Archivo Ibero-Americano, 41, 389-457.

Revuelta, M. (1985). La revolución y la Iglesia en España. Miscelánea Comillas, 43, 3-17.

Revuelta, M. (1989). Religión y formas de religiosidad. En J. M $\mathbf{M}^{\mathrm{a}}$ Jover Zamora (Dir.), Historia de España Menéndez. Pidal. Tomo XXXV. La época del Romanticismo 
(1808-1874), Volumen I. Orígenes. Religión. Filosofía. Ciencia (pp. 213-327). Madrid: Espasa-Calpe.

Revuelta, M. (1991). La recuperación eclesiástica y el rechazo anticlerical en el cambio de siglo. En J. L., García Delgado (Ed.), España entre dos siglos (1875-1931). Continuidad y cambio. VII Coloquio de Historia Contemporánea de España dirigido por M. Tuñón de Lara (pp. 213-234). Madrid: Siglo XXI.

Revuelta, M. (2000). Vivencias cristianas. En L. Ortega (Coord.), Felicidades, Jesucristo (pp. 249-251). Madrid: Biblioteca de Autores Cristianos.

Revuelta, M. (2002a). Las creencias. En J. Ma Jover Zamora (Dir.), Historia de España Menéndez Pidal. Tomo XXXVI. La época de la Restauración (1875-1902). Volumen II. Civilización y cultura (pp. 49-121). Madrid: Espasa Calpe.

Revuelta, M. (2002b). El anticlericalismo español en el siglo XIX. En P. Aubert (Ed.), Religión y sociedad en España (siglos XIX y XX) (pp. 155-178). Madrid: Casa de Valázquez.

Revuelta, M. (2004). Las congregaciones religiosas en la España contemporánea. Etapas históricas, actividades y notas bibliográficas. En B. Pellestrandi (Ed.), L'histoire religieuse en France et en Espagne. (pp. 271-294). Madrid: Casa de Velazquez, 271-294.

Revuelta, M. (2005). La Iglesia española en el siglo XIX. Desafíos y propuestas. Madrid: Universidad Pontificia Comillas.

Revuelta, M. (2007). Motivaciones y desarrollo de las exclaustraciones del siglo XIX. Revista Agustiniana 48, 519-543.

Revuelta, M. (2010). Panorama general del fenómeno de las exclaustraciones. En L. Marín de San Martín (Ed.), Le soppresioni del secolo XIX e l'Ordine Agostiniano (pp. 15-45). Roma: Institutum Historicum Agustinianum.

Revuelta, M. (2013). El restablecimiento de la Compañía de Jesús. Celebración del bicentenario. Bilbao: Mensajero.

Revuelta, M. (2014). Las órdenes religiosas en la España del siglo XX. En J. A. Escudero (Dir.). La Iglesia en la historia de España. (pp. 1197-1210). Madrid: Marcial Pons.

Revuelta, M. (2017). Enigmas históricos de la Iglesia española contemporánea. Madrid: Universidad Pontificia Comillas.

Revuelta, M. (2019). Memorias de Manuel Revuelta González. Salamanca (inédito). 